\title{
O maior, o mais ignorado, o mais combatido: o movimento das ocupações estudantis no Paraná em 2016
}

\author{
Luis Antonio Groppo ${ }^{1}$ \\ Suely Aparecida Martins ${ }^{2}$ \\ Ana Luisa Fayet Sallas ${ }^{3}$ \\ Simone de Fátima Flach ${ }^{4}$
}

\begin{abstract}
Resumo:
O artigo tem como objetivo compreender as causas do movimento de ocupações de escolas no Paraná, no 20 semestre de 2016, o segundo maior movimento de ocupações estudantis na história, em todo o mundo. A partir de revisão bibliográfica sobre o movimento paranaense e da realização de 15 entrevistas com jovens, dialogamos com Jacques Rancière e Alberto Melucci, na tentativa de melhor compreensão da dinâmica deste movimento. Aspectos conjunturais e estruturais ajudam a explicar o êxito das ocupações no Paraná, capazes de expressar a pauta de resistência à regressão nos direitos educacionais e sociais, que rejeitava a Medida Provisória de Reforma do Ensino Médio e o projeto de Emenda Constitucional do "teto de gastos". As ocupações tiveram êxito também em expressar diversas demandas e aspirações de jovens estudantes do Ensino Médio, as quais foram tomando forma desdeo período de latência do movimento. Entretanto, um bem-sucedido contramovimento, em conjunção com a repressão estatal e a judicialização do movimento, dificultou que as ocupações tivessem o mesmo impacto nas demais unidades da federação entre outubro e dezembro de 2016.
\end{abstract}

\section{Palavras-chave:}

Ocupações secundaristas. Juventude. Movimentos de juventude.

\section{The biggest, the most ignored, the most fought: the movement of student occupations in Paraná in 2016}

\footnotetext{
Abstract: The article aims to understand the causes of the movement of school occupations in Paraná, in the 2nd semester of 2016, the second largest movement of student occupations in history, worldwide. Based on a bibliographic review of the movement in Paraná and 15 interviews with young people,

1 Doutor em Ciências Sociais, Professor Adjunto da Universidade Federal de Alfenas (Unifal-MG). E-mail: Iuis.groppo@gmail.com. ORCID iD: http://orcid.org/0000-0002-0143-5167.

2 Doutora em Sociologia Política, Professora do Programa de Pós-Graduação em Educação da Universidade Estadual do Oeste do Paraná (UNIOESTE). E-mail: martins_sue@hotmail.com. ORCID iD: http://orcid.org/0000-0002-7876-6634.

3 Doutora em História, Professora Titular do Programa de Pós-Graduação em Sociologia/UFPR e do PROFSOCIO - Rede Nacional. E-mail: analuisasallas@gmail.com. ORCID iD: http://orcid.org/0000-0001-9928-6771.

4 Doutora em Educação, Docente do Departamento de Educação e do Programa de Pós-Graduação em Educação da Universidade Estadual de Ponta Grossa (UEPG). E-mail: eflach@uol.com.br. ORCID iD: http://orcid.org/0000-0002-9445-0111.
} 
we spoke with Jacques Rancière and Alberto Melucci, in an attempt to better understand the dynamics of this movement. Conjunctural and structural aspects help to explain the success of occupations in Paraná, capable of expressing the agenda of resistance to regression in educational and social rights, which rejected the Provisional Measure of High School Reform and the Constitutional Amendment Project of the "spending ceiling". The occupations were also successful in expressing various demands and aspirations of young high school students, which have been taking shape since the latency period of the movement. However, a successful countermovement, in conjunction with state repression and the judicialization of the movement, made it difficult for the occupations to have the same impact on other units of the federation between October and December 2016.

Keywords: Secondary occupations. Youth. Youth movements.

\section{El más grande, el más ignorado, el más combatido: el movimiento de ocupaciones estudiantiles en Paraná en 2016}

Resumen: El artículo tiene como objetivo comprender las causas del movimiento de ocupaciones escolares en Paraná, en el segundo semestre de 2016, el segundo mayor movimiento de ocupaciones estudiantiles en la historia, a nivel mundial. A partir de una revisión bibliográfica del movimiento en Paraná y 15 entrevistas con jóvenes, conversamos con Jacques Rancière y Alberto Melucci, en un intento por comprender mejor la dinámica de este movimiento. Los aspectos coyunturales y estructurales ayudan a explicar el éxito de las ocupaciones en Paraná, capaces de expresar el agenda de resistencia a la regresión en los derechos educativos y sociales, que rechazó la Medida Provisional de Reforma de la Escuela Secundaria y el proyecto de Enmienda Constitucional del "techo de gasto". Las ocupaciones también lograron expresar diversas demandas y aspiraciones de los jóvenes estudiantes de secundaria, que se han ido gestando desde el período de latencia del movimiento. Sin embargo, un contramovimiento exitoso, en conjunto con la represión estatal y la judicialización del movimiento, dificultó que las ocupaciones tuvieran el mismo impacto en otras unidades de la federación entre octubre y diciembre de 2016.

Palabras clave: Ocupaciones secundarias. Juventud. Movimientos juveniles.

\section{Introdução}

Esse trabalho é um esforço de, no âmbito de uma pesquisa nacional ${ }^{1}$ acerca das experiências de estudantes que ocuparam suas escolas nos movimentos de 2015 e 2016, compreender as características do movimento no Paraná no segundo semestre de 2016.

O objetivo deste artigo é compreender as causas da enorme dimensão do movimento no Paraná, que teve o maior número de instituições educacionais ocupadas na história de nosso país, e o segundo maior número em termos mundiais - perdendo apenas para a Grécia em 1990-1991, quando 2 mil escolas foram ocupadas contra-reforma educacional neoliberal (JANUÁRIO; MEDEIROS; MELO, 2019). Para tanto, buscamos analisar os dados colhidos por meio de revisão bibliográfica sobre publicações relativas às ocupações paranaenses, bem como 15 entrevistas de caráter semiestruturado concedidas em 2019 por jovens que, em 2016, ocuparam escolas estaduais no Paraná.

\footnotetext{
1 A pesquisa "Ocupações secundaristas no Brasil em 2015 e 2016: Formação e auto-formação das/dos ocupas como sujeitos políticos" é financiada pelo Conselho Nacional de Desenvolvimento Científico e Tecnológico (CNPq) e tem envolvido 12 Instituições de Ensino Superior (IES), incluindo as 4 IES do autor e autoras deste trabalho. Resultados parciais da pesquisa, ao lado de suas fontes, estão disponíveis no site da pesquisa: https://www.unifal-mg.edu.br/ocupacoessecundaristas/.
} 
Dialogamos com as ideias sobre política de Jacques Rancière, sobre movimento social de Alberto Melucci e as análises sobre o ciclo de protestos juvenis de G. Pleyers e P. Gerbaudo, ao lado da própria bibliografia que tem analisado o movimento paranaense. Para tanto, há de se destacar que esse movimento deu origem a uma onda de ocupações genuinamente nacional, com ocupações em ao menos 22 unidades da federação, enquanto os movimentos anteriores, entre novembro de 2015 e julho de 2016, foram estaduais (São Paulo, Goiás, Mato Grosso, Rio de Janeiro, Rio Grande do Sul e Ceará). Há uma pauta nacional nesta onda de ocupações iniciada no Paraná, afora o apoio de diversas organizações políticas e sindicais e movimentos sociais contrários ao regresso nas políticas sociais e na própria democracia representados pelo impeachment de Dilma Rousseff e o início do governo de Michel Temer.

No desenvolvimento deste artigo, fazemos considerações acerca das causas da segunda onda de ocupações estudantis ter se iniciado no Paraná e aí ter alcançado enorme vulto. Consideramos, na análise, elementos explicativos conjunturais e estruturais, desde específicos ao Paraná aos mais gerais, incluindo o ciclo de protestos juvenis dos anos 2010. A seguir, tratamos dos elementos presentes na fase da latência do movimento, bem como a intencionalidade dos diferentes sujeitos políticos presentes na mobilização. Enfim, descrevemos o delineamento de um poderoso contramovimento no Paraná que, associado à repressão policial e à judicialização do protesto, parece ter sido um fator chave para explicar a não repetição, nas demais unidades da federação, da mesma força das ocupações no Paraná entre outubro e dezembro de 2016.

\section{Participantes da pesquisa}

Além da revisão bibliográfica, ao longo de 2019, foram realizadas 15 entrevistas, em uma amostra orientada qualitativamente, ou seja, buscando a diversidade das formas de participação na ocupação, bem como da condição dos sujeitos e dos tipos de instituições. Evitamos assim centrar os relatos em lideranças e militantes, considerando inclusive a grande importância de ocupas independentes nesse e noutros movimentos, bem como garantir ao menos uma pequena maioria de mulheres entrevistadas, já que elas foram as principais protagonistas das ocupações.

Buscamos também diversificar os municípios e as instituições com Ensino Médio representadas nas entrevistas, considerando áreas centrais e periféricas. Nesse sentido, temos 5 pessoas entrevistadas que ocuparam escolas na Região Metropolitana de Curitiba, 4 do Sudoeste do Estado (provenientes de dois municípios), 3 da região dos Campos Gerais (que inclui Ponta Grossa), 2 do litoral (Paranaguá) e 1 do Primeiro Planalto.

Das pessoas entrevistadas, 2 estavam no 9o ano do Ensino Fundamental (EF) quando ocuparam suas escolas. Eliseu já era estudante de Educação Superior (ES) em Direito quando, na tarefa de militante da União Paranaense de Estudantes Secundaristas (UPES, da qual ainda era diretor) e da União da Juventude Socialista (UJS), participou da organização de diversas ocupações no pequeno município onde residia, no Sudoeste do estado, e na própria capital. Quanto a quem era estudante do EM quando participou da ocupação, 10 eram de escolas públicas estaduais e 2 do Instituto Federal do Paraná (IFP), em Paranaguá. Isso explica que as idades das pessoas, quando concederam a entrevista, em 2019, tenham oscilado entre 18 e 21 anos, e que apenas Eliseu destoe, com 24 anos.

Temos 8 mulheres e 7 homens. 6 se declararam heterossexuais, 4 mulheres se declararam lésbicas, 2 bissexuais (1 homem e 1 mulher), 1 LGBT (homem) e 2 não declararam (homens).

A maioria das pessoas entrevistadas ocuparam escolas centrais ou de bairros de classe média (12, sendo 4 em pequenos municípios e 8 em grandes municípios). 3 pessoas ocuparam suas escolas em bairros periféricos e 2 ocuparam uma instituição que classificamos como prestigiosa, o IFP, campus de Paranaguá.

Considerando a forma de participação na ocupação, temos a predominância de pessoas que ocuparam posições de destaque, referência ou liderança, mas que não pertenciam a entidades 
estudantis oficiais ou juventudes partidárias, que tipificamos como lideranças independentes, a saber, 7 pessoas. A seguir, pessoas que vieram a participar da ocupação depois de seu início ou não atuaram em sua organização, participando em diversas tarefas nas comissões, também sem filiação a entidades e juventudes, que tipificamos como ocupas independentes, a saber, 6 pessoas. Enfim, 3 pessoas que participaram das ocupações cumprindo funções militantes.

\section{O maior, o mais ignorado, o mais combatido}

A UBES contabilizou um total de 1.197 instituições de ensino ocupadas no 2 o semestre de 2016 no país (BOUTIN; FLACH, 2017). No Paraná foram ocupadas 850 escolas, 14 instituições de educação superior públicas e 3 Núcleos Regionais de Educação (NRE). Isso significou 80,67\% das ocupações nacionais no 2o semestre de 2016 (MATTAR, 2019).

Além de seu gigantismo, marca o movimento paranaense a sua rápida expansão e capilaridade. Segundo Stoiev (2019, p. 65-66), as ocupações se iniciaram em São José dos Pinhais e se espalharam por Curitiba e sua região metropolitana, atingindo também Ponta Grossa. A partir daí o movimento irradiou-se pelo restante do estado, alcançando o litoral e o interior. Do seu total de 399 municípios, 227 deles tiveram escolas ocupadas no Paraná, ou seja, 57\%, incluindo municípios menores. O auge das ocupações ocorreu entre 10 e 17 de outubro de 2016. Somente no dia 17, mais de 150 ocupações foram registradas (STOIEV, 2019).

Algumas pesquisas revelam a predominância, entre ocupas, dos sujeitos que também caracterizam estudantes do ensino médio público no Paraná e no país: adolescentes entre 15 e 17 anos, de camadas populares, com experiências ao menos intermitentes com o trabalho ou expectativas de breve ingresso no mundo do trabalho. Contudo, dado o enraizamento do movimento no Paraná, em vários locais foi relevante a presença de estudantes do Ensino Fundamental II entre ocupas (DAVID, 2019; PACHECO, 2018; STEIMBACH, 2018). A maioria das pessoas que entrevistamos, como visto, se enquadram neste perfil predominante.

No entanto, há certa heterogeneidade social entre ocupas, derivada principalmente da localização espacial do colégio e seu prestígio, que distinguiu escolas de periferia, escolas de bairros centrais e de classe média e, ainda, escolas prestigiosas (como o Colégio Estadual do Paraná (CEP) e o IFP), configurando que, ainda que com uma pauta comum, as ocupações foram "particularmente marcadas pelas características de classe social e local de moradia dos sujeitos que ali estavam" (OLIVEIRA, D., 2018, p. 182).

O movimento das ocupações nas escolas paranaenses, desde a sua origem, não foi homogêneo e totalizante, mas marcado, antes, por "práticas e exercícios de construção coletiva em cada bairro, de acordo com as suas características socioespaciais" (OLIVEIRA, D., 2018, p. 179). Algo semelhante Aguillea Ruiz (2016) observou no movimento dos Pinguins chilenos em 2006: não se tratou de espontaneísmo, mas também não houve um único caminho. Desse modo, especialmente nas primeiras ocupações chilenas, houve longa ou forte preparação (assim como na primeira escola ocupada no Paraná), enquanto outras escolas se engajaram de forma inesperada e até precipitada - dado o efeito de contágio, inspiração e solidariedade. Escolas prestigiosas com tradição de engajamento em lutas sociais, como o CEP e o IFP, se sentiram na obrigação de fazer parte do movimento. Danielle Oliveira (2018) e Steimbach (2018) relatam a diversidade de processos e situações, seja em escolas periféricas, seja em centrais: houve escolas em que a ocupação foi definida em assembleia, outras não; houve ocupações grandes e com envolvimento da comunidade, outras pequenas e frágeis e com resistência externa; houve ocupações que duraram um mês ou mais, enquanto outras duraram poucos dias; houve ocupações lideradas pelos grêmios, outras não. Este processo diversificado também pode ser observado em relação à participação. O que Corso (2020) constatou em Irati, na verdade, marca as diversas formas de participação nesta ação 
coletiva em todo o país, ou seja, desde lideranças e ocupas que participaram ativamente de todo o processo, passando por ocupas que se engajaram posteriormente mas participaram intensamente até o final, a ocupas que atuaram apenas de forma esporádica e intermitente.

Há dois enigmas acerca do movimento no Paraná. O primeiro, acerca do seu próprio gigantismo em comparação com as ocupações nas demais unidades da federação entre outubro e dezembro de 2016. O segundo, trazido por Januário, Medeiros e Melo (2019): apesar de seu gigantismo, houve tanto um desencontro do movimento com uma parcela significativa da sociedade civil, quanto o quase completo alheamento do sistema político em relação à pauta das ocupas. Isso levou ao fim do movimento em meados de novembro, ao menos nos colégios estaduais, sem conseguir evitar tanto a Reforma do Ensino Médio quanto a PEC do Teto de Gastos.

Buscamos levantar alguns fatores para tentar explicar o primeiro enigma, que se verá enredado ao segundo.

\section{Conjuntura, estrutura e ciclo}

Entre os elementos conjunturais, temos primeiro a conjuntura política nacional, dado que $o$ movimento vinha como reação a algumas das primeiras medidas do governo Temer. O engajamento das ocupações estudantis na oposição ao governo Temer e, na verdade, contra a nova hegemonia das elites dominantes e dirigentes que se organizava, pode ajudar a explicar porque foi, em suas pautas, solenemente ignorado pelo governo federal e poder legislativo. As principais pautas eram a revogação da Medida Provisória de Reforma do Ensino Médio (MP74/2016) e a não aprovação da Emenda Constitucional do “Teto dos Gastos" (PEC 241, depois 55/2020). Não houve efetivamente qualquer negociação de instâncias federais com o movimento, a MP 746 foi aprovada com poucas alterações como Lei 13.415/2017 (BRASIL, 2017) e a PEC 241/2016 foi aprovada de forma expressa pela Câmara e Senado, tornando-se a Emenda Constitucional 55 (BRASIL, 2016).

Apesar das entidades estudantis oficiais, que vieram a se engajar na ação, assim como diversas organizações apoiadoras - como juventudes partidárias, partidos e mesmo sindicatos do campo da esquerda -, ajudarem a inserir estas pautas na própria resistência à nova hegemonia política, a grande maioria das e dos ocupas secundaristas eram independentes, e independente foi o próprio início do movimento no Paraná.

Para secundaristas independentes, a pauta inicial e, na verdade, a principal, era contra a MP746 - o rechaço à PEC 241 se inseriu na pauta apenas uma semana após o início. Ela parece se justificar como reação a mais um dano à já frágil possibilidade de alguma igualdade de tratamento nas trajetórias escolares. Algo semelhante Rancière (2014) observara no movimento estudantil na França em 1986 contra um projeto de reforma universitária que, apesar de sua modéstia, provocou uma forte e até desproporcional reação, a se considerar apenas a proposta de lei em si, mas não a se considerar o dano nos já parcos mecanismos de igualdade existentes. Segundo Rancière (2014, p. 62), a escola, mais do que "máscara da desigualdade" (conforme a teoria da reprodução) ou o "instrumento da sua redução", é "o lugar da visibilidade simbólica quer da igualdade quer da sua negociação empírica", a despeito da diversidade de motivações que levam à sua demanda pelas pessoas (ascensão social, cidadania, cultura desinteressada, entre outras). Governantes franceses, estupefatos, assim como os do Brasil em 2015 e 2016, viram estudantes debater com grande esclarecimento as propostas da política educacional e atuar como "uma multiplicidade anônima" que "reafirmava a comunidade da partilha", transformando a questão educacional "num palco de verificação da igualdade" (RANCIÈRE, 2014, p. 65).

Os relatos sobre o dano ou lesão à igualdade formal como tendo sido aquilo que motivou o engajamento aparece de modo explícito ou implícito em todos os estados, como temos ouvido nas entrevistas. Este elemento ajuda a compreender não apenas a expansão das ocupações em todo 
o país em outubro e novembro de 2016, mas os próprios movimentos estaduais desde o final de 2015, iniciados em São Paulo contra a "Reorganização" (que fecharia quase 100 escolas e obrigaria a transferência de centenas de milhares de estudantes de suas escolas).

Entretanto, ainda não se explica o tamanho da ação coletiva no Paraná, o que nos leva a elementos da conjuntura política estadual. Destaca-se, tanto na bibliografia quanto nas entrevistas, a memória do Massacre do Centro Cívico, em 29/04/2015. Neste dia, servidoras e servidores estaduais, com apoio de estudantes, se mobilizaram em frente à Assembleia Legislativa do Paraná (ALEP) contra projeto de lei que alterava o fundo previdenciário. Houve violenta repressão pela tropa de choque do Paraná, numa ação que durou cerca de duas horas e deixou 200 pessoas feridas (FLACH; SCHLESENER, 2017). Tratava-se do coroamento dramático de uma sequência de lutas em 2015 contra medidas que, sob a justificativa de ajuste fiscal, retirava direitos trabalhistas e previdenciários de servidoras e servidores estaduais, o chamado Pacotaço (STOIEV, 2019). A indignação resultante marcou a história recente do estado e o evento tem sido rememorado por docentes e discentes (CORSO, 2020; DAVI, 2019; FIRMINO; RIBEIRO, 2019).

A política regressiva na educação marcou o governo Beto Richa desde o seu primeiro mandato e, após o Massacre, ganhou outro agravante em outubro de 2015: uma proposta semelhante à "Reorganização" feita pelo governo paulista. Diante da reação negativa, mas também diante do movimento paulista, o governo recuou (POLLI et al., 2018). Em 2016, após denúncias de fraudes e desvios de recursos públicos pela Operação Quadro Negro, o acordo firmado pelo Estado de pagamento da data-base não foi cumprido. Em meio às ocupações, docentes estaduais entraram em greve, mas com pouca adesão da categoria.

Temos, portanto, uma conjuntura política estadual, em especial no que se refere à educação, altamente regressiva e mesmo repressiva. Contudo, ela não explica por si só a enormidade do movimento, já que a pauta central tratou de medidas do governo federal.

Isso nos leva a considerar os elementos estruturais que se fizeram influentes, presentes tanto nas políticas estaduais quanto na reorientação das políticas nacionais, ao menos desde o início do segundo governo Dilma, em 2015. A crise econômica, ao lado de grandes manifestações e protestos em 2013, a acirrada disputa presidencial em 2014 e o impeachment de Dilma levaram à reorganização da hegemonia política brasileira, com a reversão da frente policlassista esboçada durante o lulismo, expurgando a influência das classes trabalhadoras (MARTINS, 2018; STEIMBACH, 2018). A crescente investida neoliberal na educação, primeiro nos estados, depois na política nacional, ilumina essa transformação estrutural.

Tanto por meio dos elementos conjunturais quanto estruturais nacionais, estudantes secundaristas se veem, ao propor sua luta contra a reforma do ensino médio, dentro de um cenário político altamente instável e hostil a protestos progressistas. Têm de fazer a sua luta e se envolver, a despeito de suas vontades, em outras lutas que não eram necessariamente as suas. De forma talvez surpreendente, ocupas buscam compreender o cenário político onde se movem, se engajam em outras pautas - como a rejeição à PEC241 - e dialogam com outros sujeitos e organizações, agindo com pragmatismo, mas também com cautela.

Deste modo, as ocupações secundaristas vão fazer parte do ciclo de protestos juvenis dos anos 2010, outro elemento explicativo estruturante. A bibliografia destaca protestos juvenis ou com intensa participação de jovens no Brasil ao menos desde as Jornadas de 2013 - "atos massivos, descentralizados, convocados pelas redes sociais, com ação direta” (PACHECO, 2018, p. 21) - e seu legado ambivalente, tanto consolidando coletivos e protestos progressistas (incluindo as primeiras ocupações, em São Paulo em 2015), quanto movimentos conservadores e de extrema-direita. As ocupações em São Paulo deram forma e fama à tática das ocupações (STOEIV, 2019) que, por sua vez, foram conscientemente aprendidas dos Pinguins chilenos (2006 e 2011) e de ocupas da Argentina (2011) (CORSO, 2020; DAVID, 2019).

Finalmente, o movimento das ocupações pode ser interpretado como parte do último suspiro do ciclo de protestos progressistas que começou, talvez, com a Primavera Árabe de 2011 em resposta 
à crise estrutural do capitalismo iniciada em 2007 (PLEYERS, 2018). Os protestos desse ciclo caracterizam-se por combinar duas tradições da esquerda que tenderam a ser eclipsadas no século XX, a saber, o anarquismo - ou neo-anarquismo, em especial pelo uso de práticas políticas táticas herdadas do movimento antiglobalização (ação direta, horizontalidade, novas Tecnologias de Informação e Comunicação [TICs]) - e o populismo democrático - com a valorização da cidadania participativa e inclusiva, mas sem lideranças personalistas. Destacam-se a práxis das ocupações, especialmente de praças públicas, certo pragmatismo mais do que rejeição nas relações com as organizações tradicionais progressistas (apesar da desconfiança) e a necessidade de enfrentar contra-movimentos regressistas da sociedade civil (sob incentivo ou em conluio com poderes políticos) (GERBAUDO, 2017).

\section{Latência e intencionalidade da ação}

Apesar da grande relevância dos elementos conjunturais e estruturais, que agem como cenário e campo de possibilidades para o protesto social, incluindo o próprio ciclo global de protestos juvenis - que alimenta novos movimentos com táticas, ideais e pautas -, há de se considerar a intencionalidade dos sujeitos que organizam e participam da ação. Essa intencionalidade, por sua vez, deve ter seus fundamentos buscados na fase da latência deste movimento das ocupações. A passagem à ação, a decisão pelo engajamento e o esforço de organização e mobilização, assim como o interesse em que protestos massivos interfiram nos rumos da política nacional, são fatores a se considerar como determinantes, em conjunção com as limitações e oportunidades que o cenário e o contexto oferecem.

As entrevistas são importantes para a compreensão da grandeza do movimento do Paraná e, diante do que tratamos no item anterior, ajudam a entender porque o movimento gerou uma poderosa corrente que, como se verá, se não fosse a cáustica contraofensiva repressiva e jurídica, provavelmente atingiria o país com a mesma intensidade. Elas, quando trazem as recordações sobre as motivações em se engajar, ajudam a compreender o que Alberto Melucci (1999) chama de latência do movimento social. Trata-se daqueles elementos forjados no cotidiano e que se acumulam dia após dia na experiência dos sujeitos e organizações, os quais preparam, organizam ou explicam o momento mais evidente, o da mobilização ou protesto (CORTILHO, 2020).

A fase de latência permite a experimentação direta de novos modelos culturais, favorece a mudança social por meio da construção de significados e da produção de códigos diferentes daqueles que prevalecem em uma sociedade. [...] A latência representa uma espécie de laboratório submerso de antagonismo e inovação. (MELUCCI, 1999, p. 54).

Surpreendentemente, são dados vários exemplos por ocupas que entrevistamos acerca da importância de algumas e alguns docentes para a sua formação política ou o "despertar" da crítica social. Nisso, ocupas do Paraná não têm se diferenciado de quem temos entrevistado em outros estados. Ou seja, há elementos da própria vida escolar "formal" ou curricular que propiciaram parte da latência do movimento das ocupações. As entrevistas destacam o trabalho formativo de algumas e alguns docentes, em especial de certas disciplinas (Sociologia e História, por vezes Geografia e até Língua Portuguesa), algo que ocorreu também nos demais estados. Temos assim um indício de formação social e política crítica promovida por parte da docência em seu trabalho pedagógico. Corso (2020) e David (2019) também trazem exemplos, em municípios do interior, da importância das discussões em disciplinas como Sociologia, Filosofia e História para fomentar a ideia da ocupação.

Ainda mais potentes parecem ter sido as motivações que conjugaram demandas e expectativas educacionais, políticas e pessoais. Elas devem ser compreendidas desde a profunda alteração nas formas de atuação dos sujeitos sociais e dos conflitos, segundo Melucci (2001). Os sujeitos constroem identidades mais transitórias e flexíveis e exibem menos vontade de tomar o poder político, 
em favor do desejo de maior controle imediato das condições de existência e do desejo de criar espaços independentes do sistema (CORTILHO, 2020).

As entrevistas revelaram uma série de motivos para participar das ocupações, mais de ordem pessoal ou individual do que de ordem coletiva e, apenas no caso de Eliseu, como cumprimento de uma função militante. Entretanto, ao longo das entrevistas, pode se revelar mais do que um motivo ou se oscilar entre distintas motivações. Mais importante, as motivações iniciais, geralmente de ordem pessoal, vão se conjugar às motivações de ordem coletiva cultivadas na latência, clarificadas durante a mobilização.

Entre motivos mais coletivos, destaca-se o posicionamento das e dos estudantes diante das ameaças ao direito à educação e diante da própria escola - precarizada e/ou autoritária. Também, como um gesto de esclarecimento à sociedade sobre o caráter pernicioso da MP746 e da PEC241, como diz Ivã: "fazer com que as pessoas entendessem o que estava acontecendo" - e até mesmo para mostrar o valor da escola - tanto as periféricas quanto os colégios prestigiosos tradicionalmente ativos politicamente. Algo que também aparece com destaque como motivação pessoal - ser ouvido e ser reconhecido como sujeito político -, tanto na bibliografia sobre as ocupações paranaenses quanto nas demais entrevistas de nossa pesquisa, também aparece nos relatos de Andréa e José (que misturam o motivo pessoal e o coletivo). Nem sempre é fácil para a análise separar o pessoal do coletivo, já que a crítica que Natália faz da MP746 é toda embasada em sua experiência individual em relação às disciplinas que seriam suprimidas como obrigatórias:

(Eu participei) Por sentir necessidade de tomar uma postura perante essas medidas que estavam sendo tomadas. [...] Então acho que foi mais nesse sentido de se mostrar resistência perante isso, e mostrar o papel dos estudantes, de que nós temos, sim, uma responsabilidade. [...]. (José).

Esse foi o momento mais revolucionário, um movimento politizado de estudantes dentro daquela escola, que fez não só que a gente fosse contra os projetos governamentais, mas contra toda aquela situação autoritária que nós vivenciávamos dentro da escola, seja do diretor, dos professores. (Gustavo).

Porque estava acontecendo com a escola e da ameaça que as matérias como a sociologia e a filosofia estavam correndo. Acho que esse foi o pior, porque foram matérias que me ajudaram a me encaixar dentro da escola. [...] E quando eu vi todo mundo falando da ocupação e usando de exemplo as ocupações que estavam acontecendo em São Paulo, aí eu fui ver tudo isso. E eu senti que aquilo, de alguma forma, tinha sentido para mim. Eu tinha um apego muito grande naquele momento com a educação, se tratando da educação pública. [...] Naquele momento, eu via a ocupação como uma estratégia mais pertinente que a gente tinha para tentar mobilizar as pessoas e, pelo menos, avisar do que estava acontecendo. (Natália).

Entre motivos mais pessoais, apareceram o desejo de interagir e participar, mesmo sem grande conhecimento prévio sobre a pauta do movimento, assim como o desejo de deixar sua marca (na escola ou na história) e até mesmo o desencargo de consciência. Entre os extremos, o caso de Eliseu "a ocupação foi mais uma agenda na minha vida" - e, ao menos em parte, os casos de Cristiane e Luís que, mesmo reconhecendo motivos pessoais, se viram, com surpresa, inesperadamente engajada e engajados em uma ação coletiva. O relato de Luís traz que nem todo o corpo discente considerava a ocupação como algo sério e ele próprio parece ter visitado a ocupação por curiosidade.

Eu levei como uma forma pessoal de interagir com a vida e na hora que eu vi que era uma razão que nós tínhamos de fazer, eu lutei. [...] Eu estava estudando (a pauta), mas não sabia exatamente o que era. Mas na hora que eu tive a compreensão exata, eu pensei: 'Vamos pra frente!' [...] se eu morrer hoje, vão chorar meus pais e meus amigos, e amanhã é um dia normal. Então, nós não somos ninguém nesse mundo. Então eu quero fazer algo. (Ivã). 
Eu tinha vontade de participar do grêmio, dessas coisas, mas eu não tinha a oportunidade. Então eu vi a ocupação como a oportunidade de eu aparecer, talvez, na escola, ou de eu fazer parte, ou das pessoas me conhecerem. (Frida).

Eu fui mais de curiosa, mais pra ver o que estava acontecendo. [...] Daí eu fui e não saí mais. [...] Eu pensei: "Ah, se daqui a alguns anos eu pensar que eu não participei disso, eu vou me sentir muito mal.” [...] No primeiro momento, foi um desencargo de consciência. (Cristiane).

Eu nunca fui de participar, de protestar. [...] mas era uma coisa que se estava falando. [...] e 'Ah, cara, vamos ver o que é?'. Estava todo mundo indo. Foi isso. [...] E daí em comecei a me interessar um pouco mais. [...] Eu fui porque o outro foi, porque chamaram ele, mas eu descobri uma causa. [...] Mas tinha gente que estava lá só por estar, só pra fazer volume. Isso era triste [...] e isso me mudou muito. (Luís).

Finalmente, deve se ater ao fato de que parte relevante de ocupas era composta por pessoas com identidades cotidianamente marginalizadas ou invisibilizadas na escola e na própria sociedade: mulheres - que tenderam a ocupar o papel de lideranças -, pessoas negras e LGBTT. Com a ocupação, estas identidades deixaram as margens do espaço escolar e também pautaram o movimento, fazendo delas, segundo Pacheco (2018), também mobilizações identitárias e não apenas redistributivas:

A gente percebeu que, majoritariamente, quem ocupava a escola eram mulheres, mulheres negras e LGBTs. Quem estava à frente das ocupações eram essas pessoas, com essas identidades, o que é muito interessante. Elas e eles são os maiores marginalizados dentro da escola, mas que naquele momento disputaram a ativa e dirigiram a ocupação. (Gustavo).

Uma das principais virtudes do movimento, em sua fase de mobilização, foi sua capacidade de articulação ou conjugação destas tantas motivações pessoais e coletivas construídas durante a latência - incluindo demandas pelo reconhecimento e pautas identitárias -, com as pautas nacionais de rejeição à MP746 e PEC241.

Vários sujeitos e organizações políticas atuaram de modo importante na passagem da fase da latência à da mobilização no movimento das ocupações no Paraná. Temos, primeiro, as entidades estudantis e seus aliados - notadamente, juventudes partidárias, partidos e organizações sindicais ligadas ao Campo Democrático-Popular. No Paraná, destacaram-se a UPES, a União Brasileira dos Estudantes Secundaristas (UBES) e algumas Uniões Municipais de Estudantes Secundaristas (UMES) - como a de Ponta Grossa -, em geral orientadas pela UJS, ligada ao Partido Comunista do Brasil (PCdoB). O PCdoB havia feito parte do arranjo no poder federal costurado pelo Partido dos Trabalhadores (PT) nos governos de Lula e Dilma. A ele e a outros grupos que faziam parte do chamado Campo Democrático-Popular, os protestos estudantis ganhavam nova dimensão: para além de oposição a políticas estaduais regressivas, uma fonte de resistência contra a nova hegemonia política representada pelo governo Temer. Não é possível dizer que ocupas independentes tenham feito este papel de forma inconsciente, ao contrário, tenderam a reconhecer a necessidade da oposição a Temer, inclusive pela postura do governo de não dialogar e, logo, de reprimir. O que independentes quase sempre rechaçaram foram as tentativas de instrumentalização das ocupas pelas entidades em busca de publicidade, falsa representação e recrutamento.

As entidades estudantis e a UJS, inclusive, organizaram ocupações isoladas no Paraná, a partir de questões específicas, de certo modo ensaiando - sem sucesso - um movimento de mais larga escala. Isso se deu em Maringá e Ponta Grossa em maio de 2016 (FIRMINO; RIBEIRO, 2016; STOIEV, 2019).

Quando teve início o amplo movimento em outubro, a UPES não foi a principal organizadora das ocupações, ainda que tenha sido importante em alguns municípios, como Londrina e Maringá. Mas ela tentou se legitimar, sem êxito perante grande parte de ocupas, como a 
interlocutora principal do Movimento no Paraná. Claro, ações das entidades foram, como sempre, importantes para ajudar na organização e orientações ao movimento, como a página no Facebook OcupaParaná - que diariamente atualizava o número de escolas ocupadas no estado. Enquanto governo e mídia comercial elegiam a UPES como interlocutora, não foi bem-sucedida sua tentativa de representar as e os ocupas, o que ficou evidenciado em Assembleia no dia 26/10/2016, em Curitiba, com representantes das ocupações. Este tipo de assembleia representativa e o desejo da UPES de exercer papel de liderança contrariavam a própria forma organizativa do movimento, que "na sua origem era autônomo, desburocratizado e estruturado com base na participação direta dos estudantes mobilizados" (DOMBROWSKI; MINUCELLI; SANTOS, 2016, p. 258). Não à toa, a assembleia foi muito tumultuada e não conseguiu dar mais organicidade ao movimento, diante do confronto entre a orientação do "centralismo democrático" das entidades estudantis que desejavam negociar com o governo estadual a forma de aplicação da MP746 no estado - e a orientação autonomista de parte relevante das e dos ocupas - que exigiam a revogação imediata da MP746 (PACHECO; SALLAS, 2019).

Coletivos autonomistas - como os antifascistas em Curitiba - tiveram presença importante no movimento das ocupações, não tanto pela quantidade de ativistas ou de escolas nas quais organizaram as ocupações, mas por suas práticas e valores políticos virem por representar melhor as demandas e anseios da grande maioria de ocupas, que eram independentes. Desde a emergência do movimento, por iniciativa de estudantes em São José dos Pinhais, ainda que sob o abrigo do APP-Sindicato (Sindicato dos Trabalhadores em Educação Pública do Paraná), sempre houve a intenção das e dos estudantes de manter o caráter independente e autônomo do movimento (FIRMINO; RIBEIRO, 2019). Dias depois da Assembleia convocada pela UPES, independentes e autonomistas se frustrariam novamente com as organizações clássicas da esquerda, quando Assembleia sindical, em 30/11, decidiu encerrar a greve docente, face a ameaça de corte de salários. Em reação, diversas ocupações na Região Metropolitana de Curitiba buscaram criar suas próprias organizações com um tom mais contundente de crítica às entidades estudantis e partidos: o CAOS (Coletivo Autonomista de Organizações Secundaristas), que teve como núcleo o CEP (que havia se tornado um centro ou referência do movimento); e o Cordão Sul, que reuniu sete escolas de região periférica de Curitiba, em torno do bairro Sítio Cercado (ALMEIDA; MARTINS, 2018).

Segundo Mara Oliveira (2020), a forma de contágio vivida pelo movimento das ocupações estudantis teve como modelo o rizoma (descentralizado, horizontal, com autonomia das partes) e não a árvore (centralizado, mais vertical, com mais dependência das partes ao centro). As tentativas, em maio, no próprio Paraná, das entidades estudantis - que se orientam politicamente pelo modelo da árvore - de dar origem a novas ondas de ocupações não tiveram sucesso, mesmo que tenham tido conquistas localizadas. Em contrapartida, tiveram sucesso as ações de caráter rizomático, por meio da iniciativa em especial de independentes e autonomistas que, tanto em São Paulo quanto nas primeiras ocupações do Paraná, tinham o anseio de que houvesse o efeito de contágio. Entretanto, os dados e relatos indicam que a atuação das entidades e juventudes partidárias também foi importante ao longo dessas ondas de ocupações, com orientações políticas e jurídicas e até mesmo na sistematização das pautas, como a que deu vazão ao movimento nacionalizado no segundo semestre de 2016.

As entrevistas feitas por nossa pesquisa, quando relatam a preparação da ocupação da escola ou como ela se deu, revela algo já anunciado pela bibliografia, ou seja, a heterogeneidade das atrizes, dos atores e das organizações envolvidas - apesar de referendarem a maior importância de independentes - e das diferentes dinâmicas das ocupações, relacionadas ao município ou local, tipo de escola, atuação do grêmio, cultura escolar, relação com a comunidade escolar e a comunidade local. As entrevistas falam de movimentos e acontecimentos que inspiraram ou levaram às ocupações: apoio ao movimento docente de 2015; manifestação contra projeto estadual baseado no Escola sem Partido; luta e conquista do passe livre estudantil em Ponta Grossa pela UMESP em 2015; 
ocupação de colégio em Ponta Grossa em maio de 2016; atos da UMESP contra governo estadual e governo Temer; ato em São José dos Pinhais contra a MP746, seguida de assembleia que decidiu pelas ocupações no município; assembleia de discussão da MP746, demandada pela secretaria da educação, que, na contramão da intenção do governo, veio por inspirar novas ocupações.

Também tratam de pessoas e organizações: docentes da escola que fazem palestra sobre o Massacre do Centro Cívico e participam de reuniões de discussão da MP746 e da PEC241; militantes destacam a atuação das suas entidades estudantis, que parecem ter tido papel importante em Ponta Grossa (UMES) e Pato Branco (UPES), mas ao menos Eliseu reconhece que não foi das entidades a iniciativa - "a gente estava acompanhando algumas ocupações e entendendo o clamor dos estudantes"; independentes reconhecem a importância do APP-Sindicato, seja no Sudoeste Paranaense, incentivando a formação de grêmios e organizando ato contra o Escola sem partido, seja em São José dos Pinhais, por abrigar curso de formação política que trouxe ocupa de São Paulo para narrar sua experiência e profissionais do Direito para tratar da MP746, assim como apoiou ato contra a MP que se tornaria o prelúdio da primeira ocupação; novamente em São José dos Pinhais, se destaca o apoio de estudantes da Universidade Tecnológica Federal do Paraná (UTFPR), inclusive participando da primeira ocupação; já em Curitiba, destaca-se a atuação de coletivos antifascistas, em especial no CEP; há ainda iniciativas bastante localizadas, mas de grande relevância, como o coletivo LGBTT criado em 2015, do qual Juliana participava, que fez uma cartilha explicativa sobre como ocupar uma escola.

A assembleia estudantil para decidir pela ocupação, apesar de recomendada pelas entidades estudantis, nem sempre foi o momento inicial da ocupação, muitas vezes oriunda da iniciativa de um grupo de estudantes, ligado ou não ao grêmio, por vezes até à revelia do grêmio. Gustavo relata que em um colégio de Pato Branco, a coordenação do grêmio, no caso, indicada pela direção, foi destituída em assembleia por se colocar contra a ocupação, alterando-se o estatuto do grêmio e prevendo eleições. Distintamente, no IFP, em Paranaguá, o grêmio promoveu diversas palestras e debates com estudantes para convencer a comunidade discente a ocupar. Nas primeiras escolas ocupadas de um município ou região, a tendência foi a de ter havido uma série de reuniões de estudo da MP746 ao lado de pessoas apoiadoras (docentes, membros do sindicato, estudantes da universidade) e de discussão da própria tática da ocupação, como em São José dos Pinhais, ainda que, como em pequeno município do Sudoeste, estudantes de colégio de periferia se anteciparam à escola que vinha se organizando há mais tempo, inclusive como forma de deixar sua marca no movimento.

As primeiras ocupações também trazem a marca da heterogeneidade dos sujeitos ocupas, como a de São José dos Pinhais, revelando a coalizão por trás da mobilização: eram de 20 a 30 pessoas, entre estudantes de diferentes colégios e da UTFPR. Nas próximas ocupações, porém, destacar-se-á sobretudo o efeito contágio. O contágio aparece em diversas entrevistas como inspiração vinda das primeiras escolas ocupadas, seja no estado, na região ou no próprio município. Como já foi dito, se tratava de algo planejado por ocupas de São José dos Pinhais, como a visita à escola de Natália e o estímulo a que ocupassem o colégio. No entanto, várias escolas começaram a ser ocupadas à revelia do primeiro grupo de ocupas: "A gente já tinha uma ideia pré-estabecida, assim: 'Ah, a gente vai ocupar esse, e depois aquele, e depois.... Foi indo muito rápido, foi uma explosão" (Luís). Para Cláudia, acabaram acontecendo ocupações desorganizadas, com pouca responsabilidade diante da pauta e da estratégia.

Forma atabalhoada de ocupação também é narrada por Juliana, mas que também indica o forte caráter de contágio que o movimento teve no Paraná. Enquanto aguardava o ônibus, em frente a outro colégio que não o seu, Juliana é reconhecida como liderança e é chamada para dentro do colégio para falar do movimento. Logo a seguir, assembleia estudantil improvisada decide pela ocupação. Enquanto isso, em Pato Branco, colégio apenas com Ensino Fundamental é ocupado por discentes, apesar de a UPES ter recomendado o contrário: "Quando eu cheguei na escola, a cena 
que eu encontrei foi a secretária da escola e a diretora ilhadas dentro da secretaria e um mar de cabecinha pequenina assim cercando aquela secretaria com palavras de ordem dizendo: 'vamos ocupar, vamos ocupar"' (Eliseu). O movimento criou uma força de contágio inusitada, mobilizando até mesmo crianças e adolescentes muito novas e novos. Até mesmo a iniciativa de uma única pessoa poderia ser suficiente para inspirar a ocupação da escola: "Partiu de mim mesmo (a iniciativa de ocupar), que aí eu comecei a ocupação, pela minha revolta. Aí que o movimento estudantil veio atrás de mim" (Andréa).

O efeito contágio foi irresistível no estado e parecia ser irresistível no país, com diversos estados logo iniciando suas ocupações estudantis. Quase todas as unidades da federação tiveram ao menos uma instituição ocupada durante os meses em que a PEC241, depois PEC55, foi tramitada na Câmara e no Senado, entre outubro e dezembro de 2016. Entretanto, o fato do movimento não se repetir nas demais unidades com o tamanho e a força do Paraná pode nos ajudar a remodelar a nossa questão. Em vez de perguntar "por que o Paraná teve uma mobilização tão grande em outubro de 2016?", poderia se perguntar, "por que o movimento nacional não teve o mesmo tamanho do Paraná em outras unidades da federação entre outubro e dezembro de 2016?"

\section{A contraofensiva}

A resposta parece residir em outro elemento a considerar em nossa análise, com o qual os protestos do ciclo global dos anos 2010 sempre tiveram de lidar: impetuosos contramovimentos, repressão estatal e processos judiciais.

A segunda onda de ocupações estudantis no Brasil, no 2º semestre de 2016, foi marcada por uma repressão estatal e paraestatal mais organizada e consequente, aproveitando a experiência acumulada por governos, forças de segurança e organizações de direita e extrema-direita no confronto com os movimentos de âmbito estadual na primeira onda. Sob a memória negativa do Massacre do Centro Cívico em 2015, o governo paranaense titubeou em usar a repressão policial. Mas o Paraná se notabilizou pela mobilização de organizações repressivas auxiliares paraestatais, incentivadas pelo próprio governo estadual e apoiadas por parte da população e até mesmo por estudantes, docentes e direções. Aí, com poucas exceções, as forças policiais só entraram em ação para cumprir mandatos de reintegração de posse.

Temos um elemento que parece decisivo para explicar por que o gigantismo do movimento no Paraná não se repetiu nas demais unidades da federação. Trata-se do acúmulo de aprendizado pelas forças de segurança com as ocupações anteriores, afora o aprendizado do modo como lidar com a opinião pública por governos, e, principalmente no caso paranaense, a bem-sucedida mobilização de um contramovimento paraestatal - o Desocupa Paraná - que funcionou ao mesmo tempo como uma mobilização de parte da sociedade civil (incluindo o apoio de parte relevante de direções, docentes, responsáveis e estudantes) e como força repressiva, tanto pela ameaça quanto pela agressão. No momento em que os movimentos nos demais estados se iniciaram e poderiam se alastrar, contramovimentos se articularam mais rápida e efetivamente. Contou também a atuação do poder judiciário, que, como em Minas Gerais e Espírito Santo, usou as soluções jurídicas adotadas no Paraná para decretar reintegrações de posse para desocupar as escolas.

O movimento em São Paulo em 2015 contra a "Reorganização" ganhou o apoio da maioria da sociedade civil. Segundo pesquisas de opinião em novembro de $2015,59 \%$ da população paulista era contrária à "Reorganização" e 55\% era a favor da tática das ocupações escolares. O mesmo não se deu no Paraná, onde a pauta foi legitimada, mas não a tática: pesquisa do Instituto Paraná, no início de novembro de 2016, apontou que, se $62,2 \%$ da população era a favor das reivindicações das e dos ocupas, $69 \%$ eram contra as ocupações e $84,2 \%$ defendiam o fim das ocupações (JANUÁRIO; MEDEIROS; MELO, 2019). 
A morte de estudante em escola ocupada de Curitiba em 24/10 teve grande destaque na imprensa, dando início a uma guinada conservadora e até mesmo dando fôlego a um governo estadual com baixíssimo apoio popular (JANUÁRIO; MEDEIROS; MELO, 2019).

Lideranças do Movimento Desocupa Paraná foram recebidas em reuniões por representantes do governo estadual e fizeram grande uso das redes sociais. Conseguiram mobilizações na base da sociedade civil contra as ocupações e fizeram inúmeras tentativas de invasão de escolas (JANUÁRIO; MEDEIROS; MELO, 2019). Segundo Steimbach (2018, p. 181), a repressão também usou da horizontalidade ensinada por ocupas, fazendo algo "incomum", a saber, "o uso da violência não pelo elemento coator do Estado, mas pela própria sociedade civil", ou seja, "grupos civis pela desocupação". Mídias comerciais, inclusive no interior, deram grande destaque ao Movimento Desocupa e legitimaram suas ações de ameaça e agressão (DAVID, 2019).

Diversas entrevistas demonstram a grande redução do número de jovens ocupas nos últimos dias das ocupações em algumas escolas, não apenas pelo cansaço e pelas ameaças, mas também por responsáveis passarem a proibir filhas e filhos de continuar a dormir ou mesmo permanecer na escola depois da morte do estudante.

A atuação do poder judiciário também foi decisiva. Inicialmente, ele tendeu a reconhecer o direito de expressão e manifestação e não acatou os pedidos de reintegração de posse para desocupar as escolas. Repetiu-se no Paraná algo que também ocorreu em São Paulo e Goiás, ou seja, houve de início algum espaço institucional contrário à hipótese do esbulho para justificar a reintegração de posse. Mas, diante da duração do movimento e de elementos como as eleições municipais e o Exame Nacional de Ensino Médio, o espaço veio a se fechar. Ainda assim, as primeiras decisões favoráveis foram importantes para o movimento se manter, já que o espaço escolar era crucial para a ação coletiva. Em contrapartida, decisões contrárias da Justiça ajudaram a minar a legitimidade do movimento (BARBOSA; TAVOLARIA, 2019). Várias liminares no final de outubro e início de novembro de 2016 foram desocupando escolas, algumas via Ministério Público e Conselho Tutelar, alegando o risco que estudantes corriam, mas em sua maioria via Vara da Fazenda Pública, com "ameaças de multas em nome daqueles que se dispuseram a assinar as atas no momento da ocupação” (FIRMINO; RIBEIRO, 2019, p. 218).

Diante das decisões judiciais, a polícia militar não mais hesitou em atuar, participando das desocupações das escolas, que tenderam a se dar de forma não conflituosa. Caso de colégio de periferia, que Ivã ocupou, revela a nova disposição repressiva. Um dia após desocuparem a escola, sob mandato judicial, Ivã e colegas tentam reocupar a escola: "Só sei que o número de policiais que chegou foi extremamente alto, eles cercaram o colégio de polícia. Eram 5 viaturas e 4 motos [...]. A polícia militar foi clara para nós: 'ou vocês vão sair ou nós vamos tirar vocês. Vocês querem que nós usemos a força ou não?’” (Ivã).

Tal conluio de dispositivos políticos e jurídicos, afora a repressão policial sempre no horizonte, parece ter sido determinante para que as ocupações nas demais unidades da federação não tivessem a mesma potência que as do Paraná neste momento. Trata-se de uma hipótese a ser mais bem testada, mas o estado da pesquisa permite considerá-la como relevante. Ela parece explicar bem os casos de Minas Gerais e Espírito Santo, em que os dispositivos repressivos estatais e paraestatais e a judicialização do movimento se assemelharam aos do Paraná, mas buscaram se antecipar à maior disseminação das ocupações. Parece que faltou também fôlego à maioria dos estados que tiveram ocupações antes de outubro de 2016 para repetir o movimento com a mesma força, como São Paulo. Em praticamente todos os estados, ficou patente algo que marcou as ocupações no Paraná: a dificuldade de conquistar o apoio da maioria da sociedade civil. Já se vivia em um contexto de maior acirramento político e enfraquecimento do campo popular-democrático - sob cerrado ataque da mídia comercial e do poder judiciário -, que levariam à vitória da extrema-direita em 2018. 


\section{Considerações finais}

A conjugação entre aspectos conjunturais e estruturais levaram ao Paraná ser, naquele momento, o lugar mais propício para o sucesso das ações que desejavam provocar uma nova onda de ocupações estudantis como tática de resistência a novos retrocessos nos direitos educacionais e sociais. Assim, explicam o porquê de ser o Paraná o lugar onde a segunda onda de ocupações, agora genuinamente nacional, se iniciou, bem como a sua grandeza e intensidade. Entretanto houve a elaboração, durante o próprio outubro de 2016, auge das ocupações paranaenses, de uma bem-sucedida conjugação entre contramovimento estimulado pela sociedade política e enraizado em parte da sociedade civil (incluindo as comunidades escolares) - ela própria em sua maioria não estando de acordo com as ocupações - e uma contraofensiva judicial que forneceria caminhos e argumentos para rápidas aprovações de pedidos de reintegração de posse nas demais unidades da federação. Isso ajuda a explicar por que as ocupações, ainda que tenham alcançado êxito na sua expansão territorial, não conseguiram repetir o mesmo gigantismo do Paraná.

Todavia, em que pese a eficiência estatal na ofensiva contra as ocupações estudantis no Paraná em 2016, que teve reflexos sobre sua reverberação em outros estados, o certo é que durante quase um mês estudantes conseguiram pautar contrarreformas regressivas que estavam em andamento no país. Nas suas dinâmicas organizativas e de sociabilidade, ocupas externaram práticas afirmativas de valorização da diferença, do desejo de uma escola menos burocrática e autoritária e mais participativa, bem como de autonomia política.

As ocupações, com seu formato organizativo, tiveram efeito de contágio, se espalhando por todo o Paraná e, depois, também chegando a outros estados. Todavia, esse processo não anulou sua heterogeneidade, que foi modelada pelas características socioespaciais de cada bairro, de cada escola e ocupante, mas também pela maneira diversificada com que ocorriam as ocupações, com grau maior ou menor de organização, envolvimento e participação de ocupas.

Elemento importante, que também ajuda a entender as ocupações, são os motivos que levaram à participação. Se à primeira vista, eles parecem dados - a contrariedade com a reforma do Ensino médio e a PEC dos gastos - na sua fase latente estão conjugados a outras motivações, às vezes, de ordem mais pessoal do que coletiva, como a vontade de ser ouvido, de participar, a preferência por disciplinas ameaçadas e até mesmo a curiosidade. Todavia, provocaram o desejo, menos ou mais consciente, em estar nas ocupações, o que contribuiu com inúmeros engajamentos e efetivas participações.

\section{Referências}

AGUILLEA RUIZ, Oscar. Movidas, movilizaciones y movimentos: Etnografia al movimento estudantil secundario en la Quinta Region. Revista Observatorio de Juventud, Santiago, v. 3, n. 11, p. 34-41, 2016.

ALMEIDA, Jane Barros; MARTINS, Marcos Francisco. As ocupações das escolas no Paraná: elementos para a retomada da grande política e dos novos projetos societários. In: COSTA, Adriane Alves Fernandes; GROPPO, Luís Antonio. O movimento de ocupações estudantis no Brasil. São Carlos: João \& Maria, 2018. p. 175-200.

BARBOSA, Samuel; TAVOLARIA, Bianca. Judiciário e reintegrações de posse de escolas ocupadas. In: JANUÁRIO, Adriano; MEDEIROS, Jonas; MELO, Rúrion (org.). Ocupar e resistir: Movimentos de ocupação de escolas pelo Brasil (2015-2016). São Paulo: Editora 34, 2019. p. 291-319.

BOUTIN, Aldimara; FLACH, Simone. O movimento de ocupações de escolas públicas e suas contribuições para a emancipação humana. Inter Ação, Goiânia, v. 42, n. 2, p. 429-446, maio/ago. 2017. Disponível em: https://www.revistas. ufg.br/interacao/article/view/45756. Acesso em: 20 jun. 2019.

BRASIL. Emenda Constitucional no 95. Altera o Ato das Disposições Constitucionais Transitórias, para instituir o Novo Regime Fiscal, e dá outras providências. Diário Oficial da União: seção 1, Brasília, DF, n. 241, p. 2, 16 dez. 2016. BRASIL. Lei no 13.415, de 16 de fevereiro de 2017. Altera as Leis [...]. Brasília, DF: Presidência da República, [2017]. 
CORSO, Angela Maria. O movimento de ocupação das escolas no interior do Paraná: o que motivou os estudantes a ocupar a escola. Entropia, Rio de Janeiro, v. 4, n. 7, jan./jun. 2020. Disponível em: http://www.entropia.slg.br/index. php/entropia/article/view/157/163. Acesso em: 6 out. 2020.

CORTILHO, Gabriel Cavallari. Do eu ao nós: a construção da identidade coletiva secundarista nas ocupações de 2015. 2020. Dissertação (Mestrado em Educação) - Universidade Estadual de Campinas, Campinas, 2020.

DAVID, Franciele Maria. Movimento das ocupações escolares: o fazer político dos jovens secundaristas no município de Francisco Beltrão/PR. 2019. Dissertação (Mestrado em Educação) - Universidade Estadual do Oeste do Paraná, Francisco Beltrão, 2019.

DOMBROWSKI, Osmir; MINUCELLI, Conrado Pereira; SANTOS, Jaqueline Aparecida Alves dos. \#OcupaParaná - as ocupações das escolas públicas paranaense em outubro de 2016. Temáticas, Campinas, v. 24, n. 47/48, p. 247-274, 2016. Dossiê Entre greves, ocupações e golpes: o Brasil de 2016. Disponível em: https://www.criticaeducativa.ufscar. br/index.php/criticaeducativa/article/view/345. Acesso em: 6 out. 2019.

FIRMINO, Veridiana V.; RIBEIRO, Márcio Moretto. Ocupações no Paraná: a luta dos estudantes contra a reforma do ensino médio e a PEC do teto dos gastos públicos. In: JANUÁRIO, Adriano; MEDEIROS, Jonas; MELO, Rúrion (org.). Ocupar e resistir: Movimentos de ocupação de escolas pelo Brasil (2015-2016). São Paulo: Editora 34, 2019. p. $197-221$.

FLACH, Simone Fátima; SCHLESENER, Anita Helena. Análise de conjuntura sobre a ocupação de escolas no Paraná a partir do pensamento de Antonio Gramsci. ETD - Educação Temática Digital, Campinas, v. 19, n. 1, p. 165-186, jan./ mar. 2017. Disponível em: https://periodicos.sbu.unicamp.br/ojs/index.php/etd/article/view/8647613/15206. Acesso em: 20 jun. 2019.

GERBAUDO, Paolo. The mask and the flag: populism, citizenism and global protest. New York: Oxford University Press, 2017.

MARTINS, Suely Aparecida. O fazer político dos jovens das classes populares: as ocupações estudantis paranaenses. Pedagógica, Chapecó, v. 20, n. 43, p. 143-167, jan./abr. 2018. Disponível em: https://bell.unochapeco.edu.br/revistas/ index.php/pedagogica/article/view/4002. Acesso em: 20 jun. 2019.

MATTAR, Kamille Brescansin. Entre vilas: a sociabilidade juvenil como produtora de sentidos em um colégio na periferia de Curitiba. 2019. Dissertação (Mestrado em Sociologia) - Universidade Federal do Paraná, Curitiba, 2019.

JANUÁRIO, Adriano; MEDEIROS, Jonas; MELLO, Rúrion. Sociedade civil, esferas públicas e desobediência civil. In: JANUÁRIO, Adriano; MEDEIROS, Jonas; MELLO, Rúrion (org.). Ocupar e resistir: Movimentos de ocupação de escolas pelo Brasil (2015-2016). São Paulo: Editora 34, 2019. p. 320-345.

MELUCCI, Alberto. A Invenção do Presente: movimentos sociais em sociedades complexas. Tradução: Maria C. A. Bonfim. Petrópolis: Vozes, 2001.

MELUCCI, Alberto. Acción colectiva, vida cotidiana y democracia. México: El Colegio de México, 1999.

OLIVEIRA, Danielle Willemann Sutil de. Entre vozes, espaços, cartografias e ações: os territórios da juventude do bairro Sítio Cercado e o ensino de Geografia. 2018. Dissertação (Mestrado em Geografia) - Universidade Federal do Paraná, Curitiba, 2018.

OLIVEIRA, Mara Aline. Ocupações secundaristas poços-caldenses: um devir menor na educação. 2020. Dissertação (Mestrado em Educação) - Universidade Federal de Alfenas, Alfenas, 2020.

PACHECO, Carolina Simões. Ocupar e resistir: as ocupações das escolas públicas como parte do ciclo atual de mobilização juvenil no Brasil. 2018. Dissertação (Mestrado em Sociologia) - Universidade Federal do Paraná, Curitiba, 2018.

PACHECO, Carolina Simões; SALLAS, Ana Luisa Fayet. E quando a experiência vira campo? Reflexões a partir da observação participante nas ocupações secundaristas. Práxis Educativa, Ponta Grossa, v. 14, n. 3, set./dez. 2019. Disponível em: https://revistas2.uepg.br/index.php/praxiseducativa/article/view/13517/209209211565. Acesso em: 6 out. 2020.

PLEYERS, Geoffrey. Movimientos sociales en el Siglo XXI: perspectivas y herramientas analíticas. Buenos Aires: CLACSO, 2018. Disponível em: http://biblioteca.clacso.edu.ar/clacso/se/20181101011041/Movimientos_sociales_siglo_XXI.pdf. Acesso em: 20 dez. 2018.

POLI, Simone et al. Novas insurgências e a luta do movimento "Ocupa Paraná". Universidade e Sociedade, Brasília, DF, ano 28, n. 62, p. 136-149, jun. 2018.

RANCIÈRE. Jacques. Os usos da democracia. In: RANCIÈRE, Jacques. Nas margens do político. Lisboa: KKYM, 2014. p. 47-68.

STEIMBACH, Allan Andrei. Escolas ocupadas no Paraná: juventudes na resistência política à reforma do Ensino Médio (Medida Provisória 746/2016). 2018. Tese (Doutorado em Educação) - Universidade Federal do Paraná, Curitiba, 2018. STOIEV, Fabiano. A experiência das ocupações no Paraná: narrativas dos estudantes secundaristas sobre a escola pública. 2019 Dissertação (Mestrado Profissional em História) - Universidade Federal do Paraná, Curitiba, 2019.

Data de submissão: 23/01/2021

Data de aceite: 25/01/2021 
